\title{
Sulama Şebekelerinin İşletme-Bakım ve Yönetim Modernizasyonunda RAP- MASSCOTE Yaklaşımı: Kahramanmaraş Sol Sahil Sulama Şebekesi Örneği
}

\author{
Firat ARSLAN* \\ Hasan DEĞíRMENCí \\ Kahramanmaraş Sütçü İmam Üniversitesi, Biyosistem Mühendisliği Bölümü, Kahramanmaraş \\ (*Sorumlu yazar e-mail:frtrsln@gmail.com)
}

Geliş Tarihi :23.09.2017

Kabul Tarihi :03.11.2017

\begin{abstract}
ÖZET : İklim değişikliği ve küresel ssınma nedeniyle su kaynaklarının etkin ve sürdürülebilir kullanımı gün geçtikte önemini artırmaktadır. Türkiye'de su kaynaklarının yaklaşık \%70'inin tarımda kullanıldığı göz önünde alındığında sulama şebekelerinin izleme ve değerlendirme çalışmalarının gereği ortaya çıkar. Bu çalışmada, Türkiye'de Kahramanmaraş ilinde bulunan Kartalkaya Sol Sahil Sulama Şebekesi RAP-MASSCOTE (Hızlı ön değerlendirme prosedürü-Kanal işletim tekniklerinde sistem ve hizmetin haritalanması) yaklaşımıyla değerlendirilmiştir. Çiftçilerin görüşlerini almak amacıyla bir anket çalışması da yapılmıştır. Sonuç olarak sulama şebekelerinin başarısını etkileyen unsurların dışsal göstergeler ile değerlendirilmesinin yanında içsel göstergelerin de göz önünde bulundurulması gerektiği tespit edilmiştir. Sulama hizmetinin memnuniyetini ölçmek amacıyla yapılan anket çalışmasından olumlu sonuçlar elde edilmiştir.
\end{abstract}

Anahtar Kelimeler: RAP, MASSCOTE, Sulama performansı, Dışsal gösterge, İ̧̧sel gösterge

\section{RAP-MASSCOTE Aproach of Modernizing Operatıon-Maintanence and Management of Irrigation Schemes: A Case Study of Kahramanmaraş Left Bank Irrigation Scheme}

\begin{abstract}
ABSRACT : The sustainable use of water resources due to climate change and global warming has become increasingly important issue. Considering that we use about $70 \%$ of the water resources in Turkey is used in agriculture, the assessment of the irrigation networks has a big precaution. In this study, the Kartalkaya Left Bank Irrigation Scheme in Kahramanmaraş province in Turkey was evaluated by RAP-MASSCOTE (Rapid Appraisal Procedure- Mapping System and Services for Canal Operation Techniques) approach. A survey was conducted to get the views of the farmers. As a result, it has been pointed out that factors affecting the success of irrigation networks should be assessed with external indicators as well as internal indicators. In addition, in order to measure the satisfaction of the given irrigation service, positive results were obtained in the survey conducted with the farmers.
\end{abstract}

Keywords: RAP, MASSCOTE, Irrigation performance, External indicators, Internal indicators

\section{GíRIŞ}

Büyük yatırımlar ile inşa edilen sulama projeleri, ülkemizin sulu tarıma geçişini hızlandırarak ve tarımsal üretimi arttırıp ülke ekonomisine katkıda bulunmayı amaçlamaktadır. $\mathrm{Bu}$ yüzden inşası tamamlanarak işletime açılan sulama şebekelerinin performansının izleme ve değerlendirilmesi büyük önem taşımaktadır (DSİ, 2015a). Birleşmiş Milletler Gıda ve Tarım Örgütü, Dünya Bankası, Uluslararası Sulama Yönetimi Enstitüsü ve Uluslararası Drenaj Komisyonu gibi kuruluşlar sulama yönetiminin etkin izleme ve değerlendirmesi üzerinde çalışan önemli kurumlardır. Birçok ülkede, uzmanlar, yöneticiler, ulusal planlamacilar ve karar vericiler sulama şebekelerini izleme ve değerlendirme sistemi yardımı ile iyileştirilmesini tartı̧̧maktadırlar (Değirmenci, 1997).

FAO, orta ve büyük ölçekli sulama şebekelerini geliştirmek amacıyla MASSCOTE yaklaşımını geliştirmiştir. MASSCOTE yaklaşımı onbir aşamadan oluşmaktadır. $\mathrm{Bu}$ aşamaların birincisi RAP'tır (Renault ve ark., 2007). RAP, dışsal ve içsel performans göstergeleriyle sulama şebekelerini değerlendirmede kullanılan bir yöntemdir (Burt, 2001). Birçok araştırmacı, sulama şebekelerini dışsal göstergelerle değerlendirmiştir (Burt ve Styles, 1998;
Murrey-Rust ve Svedsen, 2001; Değirmenci, 2004; Clemmens ve Molden, 2007; Konukçu ve Şener, 2007; Borgia ve ark., 2013; Sönmezyıldız ve Çakmak, 2013). Dışsal performans göstergeleri ile sulama şebekeleri tam olarak değerlendirilemediğginden içsel performans göstergelerinin de kullanılması gerekmektedir (Molden ve ark., 1998; Burt, 2001; Renault ve ark., 2007). İçsel performans göstergeleri ile sulama kanallarının genel durumu, araziye su dağıtımı, sulama teknisyenlerinin performansı ve yöneticilerin görüşleri gibi dışsal göstergeleri etkileyen önemli faktörler incelenmektedir.

$\mathrm{Bu}$ çalışmanın amacı, Kartalkaya Sol Sahil sulama şebekesini RAP-MASSCOTE yaklaşımı ile performans değerlendirmesi yapmaktır. Bu yöntem ülkemizde ilk kez kullanılmış olup anılan sulama şebekesinde su dağıtım hizmetinin geliştirilmesi için öneriler verilmiş, sistemin ekonomik ve finansal durumunun incelenmesi hedeflenmiştir. Dişsal göstergelerin hesaplanması sulama şebekesi hakkında genel bir değerlendirme amacıyla yapılmıştır. İçsel göstergelerin hesaplanması ise sulama şebekelerinde sulama birliği etkinliği, hizmet kalitesi, hizmet güvenirliği ve su iletim hizmeti kalitesini 
Sulama Şebekelerinin İşletme-Bakım ve Yönetim Modernizasyonunda RAP-MASSCOTE Yaklaşımı: Kahramanmaraş Sol Sahil Sulama Şebekesi Örneği

değerlendirmek amaciyla yapılmıştır. Ayrıca, çiftçilerin görüşleri alınarak sulama şebekesinden alınan su dağıtım hizmetinin değerlendirilmesi amaçlanmıştır.

\section{MATERYAL VE YÖNTEM}

Araştırma, Doğu Akdeniz Bölgesinde yer alan Kahramanmaraş iline bağlı Pazarcık ilçesinde bulunan Kartalkaya Sol Sahil sulama şebekesinde 2015 yılında yürütülmüştür. Araştırma materyalini Kahramanmaraş ilinin güneydoğusunda bulunan Kartalkaya Sol Sahil sulama şebekesi alanı (12000 ha alanı, net sulama alanı 11600 ha) oluşturmaktadır.

\section{Dışsal göstergelerin hesaplanması}

Bu çalışmada, Burt (2001) tarafından ayrıntıları verilen RAP-EXCEL tablosunda kullanilan göstergelerle değerlendirmeler yapılmıştır. $\mathrm{Bu}$ göstergelere ait hesaplama yöntemleri ve gereksinim duyulan verilerden $\mathrm{Su}$ Dağıtım Performans Göstergeleri (Çizelge 1), Finansal Göstergelerin Hesaplanması (Çizelge 2), Tarımsal Üretim ve Ekonomik Göstergelerin Hesaplanması (Çizelge 3) şeklinde çizelgelerde verilmiştir (Burt, 2001).

Çizelge 1. Su dağıtım performans göstergeleri

\begin{tabular}{l|c}
\hline Gösterge & Tanım \\
\hline Sulama alanına dağıtılan yıllık sulama suyu miktarı $\left(\mathrm{m}^{3} \mathrm{ha}^{-1}\right)$ & $\frac{\text { Sisteme saptırılan toplam su miktarı }}{\text { Sulama alanı }}$ \\
Sulanan alana dağıtılan yıllık sulama suyu miktarı $\left(\mathrm{m}^{3} \mathrm{ha}^{-1}\right)$ & $\frac{\text { Sisteme saptırılan toplam su miktarı }}{\text { Sulanan alan }}$ \\
Yıllık su temini oranı & $\frac{\text { Sisteme saptırılan toplam su miktarı }}{\text { Toplam sulama suyu ihtiyacı }}$ \\
Su iletim kapasitesi & Ana kanalın maksimum debisi \\
\hline
\end{tabular}

Çizelge 2. Finansal göstergeler

\begin{tabular}{|c|c|}
\hline Gösterge & Tanım \\
\hline \multirow[t]{2}{*}{ Yatırımın geri dönüşüm oranı } & Toplanan su ücretleri \\
\hline & $\overline{\text { Toplam işletim ve bakım ve yönetim masrafları }}$ \\
\hline \multirow[t]{2}{*}{ Bakım masraflarının gelire oranı } & Bakım masrafları \\
\hline & $\overline{\text { Toplanan su ücretleri }}$ \\
\hline \multirow{3}{*}{$\begin{array}{l}\text { Birim alana düşen işletme-bakım ve yönetim masrafları ( } \$ \text { ha }^{-} \\
{ }^{-} \text {) } \\
\text { Personel yıllık toplam maliyeti }\left(\$ \text { personel }^{-1}\right)\end{array}$} & Toplam işletme, yönetim ve bakım masrafları \\
\hline & $\begin{array}{c}\text { Sulama alanı } \\
\text { Calışanların toplam yıllık maliyeti }\end{array}$ \\
\hline & Toplam çalışan sayısı \\
\hline \multirow[t]{2}{*}{ Su ücreti toplama performans1 } & Toplanan su ücretleri \\
\hline & $\overline{\text { Toplanması gereken su ücretleri }}$ \\
\hline Birim sulanan alana düşen çalışanlar (personel ha ${ }^{-1}$ ) & Toplam projede çalışan sayısı \\
\hline
\end{tabular}

Çizelge 3. Tarımsal üretim ve ekonomik göstergeler

\begin{tabular}{|c|c|}
\hline Gösterge & Tanım \\
\hline Sulama alanı eșdeğer brüt üretim değeri $\left(\$ \mathrm{ha}^{-1}\right)$ & Eşdeğer brüt üretim değeri \\
\hline Fiilen sulanan alan eşdeğer brüt üretim değeri $\left(\$ \mathrm{ha}^{-1}\right)$ & $\begin{array}{c}\text { Sulama alanı } \\
\text { Eşdeğer brüt üretim değeri }\end{array}$ \\
\hline \multirow{5}{*}{$\begin{array}{l}\text { Birim sulama suyuna karşılık eşdeğer brüt üretim değeri ( } \$ \\
\left.\mathrm{~m}^{-3}\right) \\
\text { Saptırılan birim sulama suyuna karşılık eşdeğer brüt üretim } \\
\text { değeri }\left(\$ \mathrm{~m}^{-3}\right) \\
\text { Bitki su tüketimine karş1lık eşdeğer brüt üretim değeri }\left(\$ \mathrm{~m}^{-3}\right)\end{array}$} & \multirow{3}{*}{$\begin{array}{c}\text { Eşdeğer brüt üretim değeri } \\
\text { Saptırlan toplam sulama suyu miktarı } \\
\text { Eşdeğer brüt üretim değeri }\end{array}$} \\
\hline & \\
\hline & \\
\hline & $\begin{array}{l}\overline{\text { Sisteme saptırılan toplam su miktarı }} \\
\text { Eşdeğer brüt üretim değeri }\end{array}$ \\
\hline & Bitki su tüketimi \\
\hline
\end{tabular}




\section{Eşdeğer brüt üretim değerinin hesaplanması}

Sulama şebekeleri arasında ya da aynı şebekenin yıllar içinde performansının karşılaştırmasını yapabilmek için eşdeğer brüt üretim değeri hesaplanmaktadır. Eşdeğer brüt üretim değerinin hesaplanmasında araştırma bölgesinde veya ülkede en çok yetiştirilen bitki referans alınarak diğer bitkiler standardize edilmektedir. Örneğin bir ülkede domatesin yerel fiyatı buğdayın yerel fiyatının üç katı olduğu durumda; 10 ton domatesin üretim değeri 30 ton buğdaya eşdeğerdir. Sonuç olarak hesaplanması amaçlanan otuz ton buğdayın dünya fiyatları göz önünde bulundurulduğunda ne kadar kazanç sağlanacağıdır. Eşdeğer brüt üretim değeri Eşitlik 1 ile hesaplanmıştır (Molden ve ark., 1998). $E B \ddot{U} D=\left(\sum_{b i t k i} A_{i} Y_{i} * \frac{P_{i}}{P_{b}}\right) * P_{\text {Dünya }}$
Eşitlikte: $\mathrm{EBÜD}=$ Eşdeğer brüt üretim değeri, (\$/ha), $\quad A_{i}=i$ bitkisinin ekim alanı (ha), $Y_{i}=i$ bitkisinin verimi $\left(\mathrm{t} \mathrm{ha}^{-1}\right), \mathrm{Pi}=\mathrm{i}$ bitkisinin yerel pazar fiyatı $\left(\$ \mathrm{t}^{-1}\right), \mathrm{Pb}=$ Eşdeğer alınan bitki yerel fiyatı $\left(\$ \mathrm{t}^{-}\right.$ $\left.{ }^{1}\right), P_{\text {Dünya }}=$ Eşdeğer alınan bitki dünya fiyatı $\left(\$ t^{-}\right.$ ${ }^{1}$ )'dur.

\section{İcsel Göstergelerin Hesaplanması}

Burt ve Styles (1998), sulama şebekeleri içinde performans değerlendirme için sadece dışsal göstergelerin yeterli olmadığını aynı zamanda içsel göstergelerin de kullanılması gerektiğini belirtmiştir. Kartalkaya Sol Sahil sulama şebekesinde içsel göstergeleri hesaplamak için RAP-EXCEL tablosu kullanılmıştır (ITRC, 2016). Çizelge 4'te içsel göstergelerin hesaplamaların yapılması için kullanılan referans alınan değerlendirme kriterleri verilmiştir.

Çizelge 4. Alt göstergelerin değerlendirilmesi (Burt, 2001 ve Renault ve ark., 2007; ITRC,

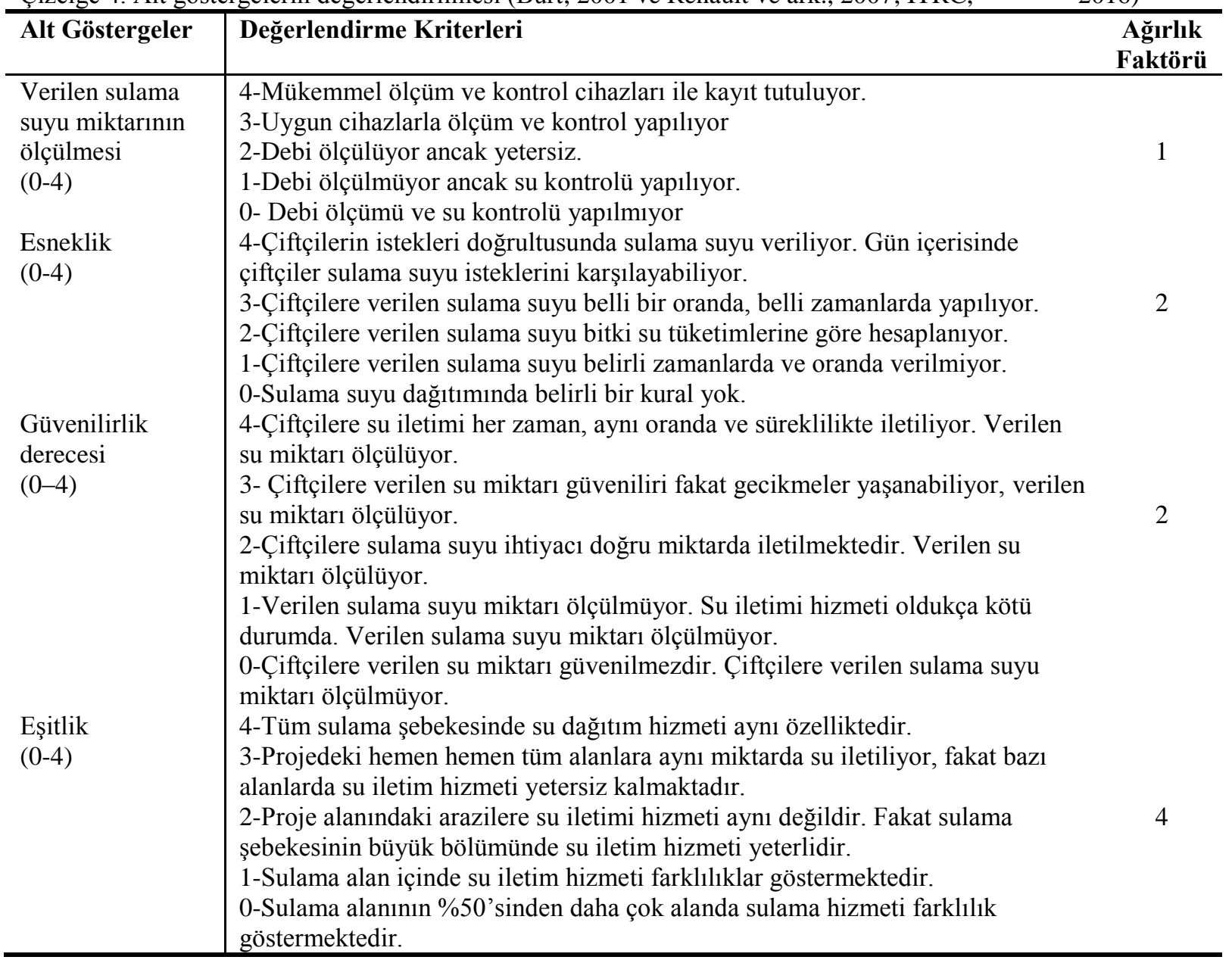

Çiftçilerin görüşlerinin belirlenmesi

Kartalkaya Sol Sahil Sulama Birliği hizmet alanında 2015 yılında 1024 kayıtlı çiftçi bulunmaktadır. $\mathrm{Bu}$ çiftçilerin sulama hizmeti hakkında görüşlerinin belirlenmesi için anket çalışması yapılmıştır. Araştırmanın örnek hacminin 
Sulama Şebekelerinin İşletme-Bakım ve Yönetim Modernizasyonunda RAP-MASSCOTE Yaklaşımı: Kahramanmaraş Sol Sahil Sulama Şebekesi Örneği

belirlenmesinde örnek hacmi formülü (Eşitlik 2) kullanılmıştır (Miran, 2003).

$$
n=\frac{N p(1-p)}{(N-1) \sigma_{p_{X}}^{2}+p(1-p)}
$$

$\sigma_{p_{x}}^{2}=$ Oranın varyansı, $\mathbf{n}=$ Örnek hacmi, $\mathbf{N}=$ Ana kitlenin birey sayısı, $\mathbf{p}=$ Oran (p: 0.5 alınmıştır)

\section{ARAŞTIRMA BULGULARI \\ Dışsal Göstergeler}

$\mathrm{Su}$ dağıtım performans göstergelerinin hesaplanan değerleri Çizelge 5'te verilmiștir. Araştırma alanında sulama oranı \%71'tir, 10687 ha alan için sulama beyannamesi (beyannamesi verilme oranı \%88.9 ) verilmiştir.

Çizelge 5. Su dağıtım performans göstergeleri

\begin{tabular}{l|l}
\hline Gösterge adı & Gösterge değeri \\
\hline Sulama alanına dağıtılan yıllık sulama suyu miktarı & $6743.97 \mathrm{~m}^{3} \mathrm{ha}^{-1}$ \\
Sulanan alana dağıtılan yıllık sulama suyu miktarı & $9572.93 \mathrm{~m}^{3} \mathrm{ha}^{-1}$ \\
Brüt yıllık su temini oranı & 2.68 \\
Su iletim kapasitesi & 1.10 \\
\hline
\end{tabular}

Sönmezyıldız ve Çakmak (2013), Beyazaltın sulamasında birim sulama alanına dağıtılan yıllık sulama suyu miktarını $4311.02 \mathrm{~m}^{3} \mathrm{ha}^{-1}$ olarak bulmuşlardır. DSİ (2015b), 2015 raporlarına göre birim alana düşen sulama suyu miktarı Göksun sulamasında $7648 \mathrm{~m}^{3} \mathrm{ha}^{-1}$, Andirın sulamasında 8751 $\mathrm{m}^{3} \mathrm{ha}^{-1}$, Keysun sulamasinda $5792 \mathrm{~m}^{3} \mathrm{ha}^{-1}$, Kayacık sulamasında $6730 \mathrm{~m}^{3} \mathrm{ha}^{-1}$ dır. Araştırma alanında ise bu gösterge $9572.93 \mathrm{~m}^{3} \mathrm{ha}^{-1}$ olarak hesaplanmıştır.

DSİ (2015b), raporlarına göre Kahramanmaraş'ta sulanan alana dağıtılan yıllık sulama suyu miktarı Sağ Sahil sulamasında 7062.41 $\mathrm{m}^{3} \mathrm{ha}^{-1}$, Așağı Andırın sulamasında $8750.73 \mathrm{~m}^{3} \mathrm{ha}^{-1}$, Göksun sulamasında ise $7644.19 \mathrm{~m}^{3} \mathrm{ha}^{-1}$ dir. Araştırma alanında bu değer diğer sulama şebekelerine göre daha fazladır. Bu durum bölgede yağışların fazla olması nedeniyle sulama şebekesine Kartalkaya Barajından daha fazla miktarda sulama suyu alması ve çiftçilerin aşırı su alma isteği ya da eğilimi ile açıklanabilir.

Araştırma alanında, brüt yıllık su temin oranı 2.68 olarak hesaplanmıştır. Değirmenci (2001), ülkemizde devredilen sulama şebekelerinde brüt yıllık su temin oranını 0.91-7.15 arasında; Abdullah ve ark. (2007), su temin oranını Malezya'da 6 farklı sulamada ortalama 2.93 olarak oldukça yüksek bulmuşlardır. Sönmezyıldız ve Çakmak (2013), Beyazaltın sulamasında bu değeri 1.60 olarak hesaplamışlardır. Çalışmada su temin oranının yüksek olduğu görülmektedir. $\mathrm{Bu}$ oranı 1'e yaklaştırmak için borulu iletim sistemleri ve basınçlı sulama yöntemleri kullanımı arttırılmalıdır. Araştırma alanının su iletim kapasitesinin 1'den büyük olması sulama kanallarının su taşıma kapasitesinin yeterli olduğunu göstermektedir.

Çizelge 6. Finansal göstergeler

\begin{tabular}{l|l}
\hline Gösterge adı & Gösterge değeri \\
\hline Yatırımın geri dönüş oranı & 1.09 \\
Bakım masraflarının gelire oranı & 0.28 \\
Birim alana düş̧en işletme, bakım ve yönetim masrafı & $89.26 \$ \mathrm{ha}^{-1}$ \\
Personelin yıllık toplam maliyeti & $8423.96 \$$ personel $^{-1}$ \\
Su ücreti toplama performansı & 0.89 \\
Sulanan alana düşen personel sayısı & 0.0028 personel ha $^{-1}$ \\
\hline
\end{tabular}

Çalışmada hesaplanan finansal göstergeler Çizelge 6'da verilmiştir. Molden ve ark. (1998), on sekiz sulama şebekesinde yaptığı çalışmalarda yatırımın geri dönüş oranını 1'e yakın, çiftçi sulamalarında 0.3-0.5 arasında, devlet sulamalarında 0.28-1.39 arasında bulmuşlardır. Çakmak (2002), Ceylanpınar İkicırcıp sulama şebekesinde yatırımın geri dönüş oranını 1.05-2.11 arasında tespit etmiştir. Beyribey (1997), Devlet Sulama Şebekelerinde yatırımın geri dönüş oranını 0.29-0.91 ve Türkiye ortalamasını 0.65 olarak hesaplamıştır. Araştırmada elde edilen değerler, Kartalkaya Sol Sahil Sulama Şebekesinde elde edilen gelirin işletme bakım ve yönetim masraflarını karşıladığını ve ülke ortalamasının üstünde olduğunu göstermektedir. 
Sönmezyıldız ve Çakmak (2013), Beyazaltın sulamasında bakım masraflarının gelire oranını 0.80 ve Nalbantoğlu ve Çakmak (2007), Akıncı sulamasında 0.25-0.11 arasında hesaplamıştır. Kartalkaya Sol Sahil Sulama Şebekesinde çalışan personelin kalifiye olması, gerekli donanım, alet ve ekipmanlara sahip olması bakım masraflarını azalttığı söylenebilir.

Kartalkaya Sol Sahil Sulama Şebekesine ait her bir personelin 2015 yılı için maliyeti 8423.96 \$ olarak bulunmuştur. $\mathrm{Bu}$ göstergeyi hesaplamak amacıyla yıllık maliyete, tüm idari personel giderleri ve çalıştırılan tüm personel giderleri dâhil edilmiştir. Nalbantoğlu ve Çakmak (2007), Akıncı sulama şebekesinde çalıştırılan her bir elemanın yıllık maliyetini 1091.09-8658.84 \$ arasında tespit etmiştir ve Sönmezyıldız ve Çakmak (2013), Beyazaltın sulamasında 4926.1 \$ olarak saptamıştır. Nalbantoğlu (2006), Akıncı sulamasında bu değeri 22.56-108.61 \$ ha $^{-1}$ arasında hesaplamıştır. Sönmezyıldız ve Çakmak (2013), Beyazaltın sulamasında 1.00 ile en yüksek, Emel (2010), Aşağı Seyhan ovasında 0.70-0.93 arasında, DSİ (2015b), Kartalkaya Sağ Sahil sulamasında 0.89, Aşağı Andırın sulamasında 0.69 olarak tespit edilmiştir. Kartalkaya Sol Sahil Sulama şebekesinde gelir toplama performansı 0.89 ile iyi olduğu söylenebilir. Ödenmeyen sulama ücretleri bir yıl sonraki sulama beyanı verilirken ödendiği düşünüldüğünde bu oran optimuma yakındır.

Eşdeğer brüt üretim değeri araştırma alanında 18,268,466.9 \$ olarak hesaplanmıştır. Değirmenci (2001), Türkiye'de devredilen sulama şebekelerini büyüklük gruplarına ayırmıştır. $\mathrm{Bu}$ gruplar incelendiğinde sulama alanı eşdeğer brüt üretim değeri 66 şebekede 1000-2000\$ ha ${ }^{-1}$ arasında, 40 şebekede 2000-3000\$ ha ${ }^{-1}$ ve 38 şebekede $3000 \$$ ha $^{-}$ ', dan fazla olduğu görülmektedir. Renault ve ark. (2007), yaptıkları çalışmada bu göstergeyi Hindistan'da bulunan Jaunpur sulama sisteminde 770 $\$$ ha $^{-1}$ olarak ve FAO (2009), Hindistan'da bulunan Narayanpur sulama şebekesinde bu değeri 1206 \$ ha 1 olarak hesaplamıştır. Tanrıverdi ve ark., (2001), Türkiye'de bazı sulama şebekeleri için bu değeri 722013 \$ ha ${ }^{-1}$ arasında; Nalbantoğlu (2006), Akıncı sulamasında yaptığ 1 çalışmada 1454.29-2970.46 \$ ha1 arasında; Abdullah ve ark. (2007), Malezya'da bulunan Tanjung Karang Rice sulama sistemi olarak adlandırılan 6 sulama şebekesinde sirasiyla 1471 \$ $\mathrm{ha}^{-1}, 651 \$ \mathrm{ha}^{-1}, 792 \$ \mathrm{ha}^{-1}, 847 \$ \mathrm{ha}^{-1}, \$ \mathrm{ha}^{-1}$, ve 1032 $\$$ ha $^{-1}$ olarak hesaplamışlardır. Araştırma alanında hesaplanan bu göstergenin (2235.49 $\$ \mathrm{ha}^{-1}$ ) orta düzeyde olduğu söylenebilir.

Çizelge 7. Tarımsal üretim ve ekonomik göstergeler

\begin{tabular}{l|l}
\hline Gösterge adı & Gösterge değeri \\
\hline Sulama alanı eşdeğer brüt üretim değeri & $1574.87 \$ \mathrm{ha}^{-1}$ \\
& $2235.49 \$ \mathrm{ha}^{-1}$ \\
Fiilen sulanan alan eşdeğer brüt üretim değeri & $0.23 \$ \mathrm{~m}^{-3}$ \\
Saptırılan birim sulama suyu miktarına karşılık eşdeğer brüt üretim değeri & $0.62 \$ \mathrm{~m}^{-3}$ \\
Bitki su tüketimine karşılık eşdeğer brüt üretim değeri & \\
\hline
\end{tabular}

Tanrıverdi ve ark., (2001), Türkiye genelinde bazı sulama şebekelerinde saptırılan birim sulama suyuna karşıllk eşdeğer brüt üretim değerini 0.01 $0.85 \$ \mathrm{~m}^{-3}$ arasında hesaplamışlardır. Değirmenci (2001), bu değeri ülkemizde devredilen sulama şebekelerinde en yüksek 1.84-1.39 $\$ \mathrm{~m}^{-3}$ arasında, en düşük 0.2-0.8 $\$ \mathrm{~m}^{-3}$ arasında hesaplamıştır. Araştırma alanında ise bu değer $0.23 \$ \mathrm{~m}^{-3}$ olarak düşük performans göstermiştir. Toplam yıllık eşdeğer brüt üretim değerinin bitki su tüketimine bölünmesi ile bitki su tüketimine karşılık eşdeğer brüt üretim değeri hesaplanmaktadır. Kartalkaya Sol Sahil sulama şebekesine ait birim bitki su tüketime karşılık eşdeğer brüt üretim değeri $0.62 \$ \mathrm{~m}^{-3}$ olarak hesaplanmıştır.

\section{İçel Göstergeler}

İçsel göstergelerin belirlenmesi için öncelikle EXCEL hesap tablosunda bulunan alt göstergeler değerlendirilmiştir. $\mathrm{Bu}$ değerlendirmeler Sulama Birliğinde çalışan personelden alınan bilgiler ve arazide yapılan gözlemler ile yapılmıştır.

Hesaplanan içsel göstergeler Sunsari Morang ve Upper Krishna Sulama Şebekeleri ile yapılan karşılaştırmalar Çizelge 8'de verilmiştir (FAO, 2009).

Kartalkaya Sol Sahil Sulama Şebekesi içsel gösterge performans değerleri diğer sulama şebekelerinden daha yüksektir. Göz önünde bulundurulan üç sulama projesinin ortak özelliği gerçekte ve belirtilen içsel gösterge değerlerinin her şebeke için farklı değerler göstermesidir.

Upper Krishna ve Sunsari Morang Sulama Şebekeleri gelişmemiş işletim ve yapıya sahip olması bu durumu açıklayabilir. Ayrıca Türkiye'de RAPMASSCOTE yaklaşımı çalışmaları yaygın değildir. 
Sulama Şebekelerinin İşletme-Bakım ve Yönetim Modernizasyonunda RAP-MASSCOTE Yaklaşımı: Kahramanmaraş Sol Sahil Sulama Şebekesi Örneği

Çizelge 8. İçsel göstergeler

\begin{tabular}{|c|c|c|c|}
\hline & \multicolumn{3}{|c|}{ Gösterge değeri (0-4) } \\
\hline Gösterge & Kartalkaya Sol Sahil & Upper Krishna & Sunsari Morang \\
\hline Araziye su dağıtımı (gerçekte) & 2.6 & 1.25 & 0.7 \\
\hline Araziye su dağıtımı (belirtilen) & 3.0 & 2.5 & 1.5 \\
\hline $\begin{array}{l}\text { Ana kanaldan sekonder kanallara su } \\
\text { saptırılması (gerçekte) }\end{array}$ & 3.0 & - & 1.7 \\
\hline $\begin{array}{l}\text { Ana kanaldan sekonder kanallara su } \\
\text { saptırılması (belirtilen) }\end{array}$ & 3.2 & - & 2.0 \\
\hline $\begin{array}{l}\text { Ana kanalda su saptırma yapıları } \\
\text { donanımı }\end{array}$ & 3.2 & 1.9 & 1.2 \\
\hline Ana kanalda genel durum & 3.4 & 1.87 & 1.6 \\
\hline $\begin{array}{l}\text { Sekonder kanalda su saptırma yapıları } \\
\text { donanımı }\end{array}$ & 3.2 & 1.2 & 1.5 \\
\hline Sekonder kanalda genel durum & 3.1 & 2.2 & 1.6 \\
\hline
\end{tabular}

\section{Çiftçi Görüşleri}

Örnek hacmi \%95 güven aralı̆̆ı ve \%10 hata payı ile 88 olarak hesaplanmıștır. Likert tipi sorulara güvenilirlik analizi yapılmış ve Cronbah's Alpha istatistiği 0.978 olarak bulunmuştur ki bu sonuç anket çalışmasının güvenilir bir ölçeğe sahip olduğunu göstermektedir. Çiftçilere yöneltilen "Sulama kanallarınız yeterli mi?" sorusu sorulmuştur. Katılımcıların verdiği yanıtlara bakıldığında; çiftçilerin \%50.8'i sulama kanallarının yeterli olduğunu, \%36.9'u kismen yeterli olduğunu, $\% 12.3$ 'ü ise yetersiz olduğunu belirtmiştir. Kullanıcılara yöneltilen "Yeterli su alabiliyor musunuz?" sorusuna verdiği cevaplar incelendiğinde; çiftçilerin \%44.6's1 yeterli su aldığını düşünmekte, kısmen yeterli cevabını verenlerin oranı \%44.6'dır, yetersiz cevabını veren katılımcılar ise \%10.8'lik bir dilimi oluşturmaktadır. Katılımcılara yöneltilen "Zamanında sulama suyunuzu alabiliyor musunuz?" sorusuna evet cevabinı verenler \%38.5'lik, kısmen evet cevabinı verenler \%49.2, hayır cevabını verenler ise $\% 12$ 'lik dilimi oluşturmaktadır.

\section{SONUC}

Günümüzde su kaynaklarının doğru ve etkin kullanılması önemini her geçen gün daha da arttırmaktadır. Bu yüzden sulama şebekelerinin iyileştirilebilmesi, mevcut durumunun belirlenmesi ve değerlendirmesi önemli bir konudur. $\mathrm{Bu}$ değerlendirmeler yapılırken göstergelerin ulusal ve uluslararası olması, sulama projelerinin izleme ve değerlendirmesinde büyük kolaylıklar sağlamaktadır. Yapılan araştırmada Kartalkaya Sol Sahil Sulama Şebekesinde RAP-MASSCOTE yaklaşımı ile Dışsal Göstergeler ve İçsel Göstergeler araştırılmıştır. Su iletim kapasitesi araştırma alanında 1.18 olarak saptanmıştır. Bu oranın 1'den büyük olması sulama kanallarının su iletim kapasitesinin, su ihtiyacının maksimum olduğu zamanda yeterli göstermektedir. Yatırımın geri dönüş oranı Kartalkaya Sol Sahil sulama şebekesinde 1.09 olarak tespit edilmiştir. Kartalkaya Sol Sahil sulama alanı içsel performans gösterge değerleri; ana kanalda ortalama 3.4 olarak hesaplanmıştır. Sonuçlar incelendiğinde araziye su dağıtımı ve ana kanalda tüm göstergelerde genel durumun iyi olduğu görülmektedir. Araştırma alanında çalışan su dağıtım teknisyenlerinin ve diğer tüm personelin kontrol edilmesi, çiftçilerle ilişkilerin iyi olması, kanal bakım ve onarımlarına özen gösterilmesi gösterge değerlerinin yüksek olmasında etkili olmuştur. Sekonder kanalda genel durum 3.1 olarak hesaplanmıştır. Sekonder kanal üzerinde bulunan çek yapıları ve prizleri işletiminin kolay olması, bakım, onarımın iyi olması, saptırılan su miktarının su dağıtım teknisyenleri tarafindan dikkatlice kontrol etmesi performans değerlerinin yüksek olmasında etkili olduğu söylenebilir. Sekonder kanal üzerinde bazı bölgelerde yabancı otların ve kırıkların bulunması bu kanal düzeyinin negatif yönleridir. Ancak performans göstergelerinin yüksek çıkmasında sekonder kanal servis yollarının iyi olması, bakım, onarım ekipmanlarının varlığ etkili olduğu söylenebilir. Araştırma alanında tüm tersiyer kanalların incelenmesi mümkün olmadığından bu kanal üzerinde çalışma yapılmamıştır. Zamanında sulama suyu alamadığını belirten katılımcıların yüzdesinin düşük olma sebeplerinin bazıları; sulama beyanın zamanında yapılmaması, ekim dikim zamanlarının diğer çiftçilerle çakışması bu nedenle aynı zamanda fazla sulama ihtiyacının oluşması ve gübrelemeden hemen sonra su isteklerinin fazla olmasıdır.

RAP-MASSCOTE yaklaşımının, sulama şebekelerinin tanı aşamasında başarılı bir yöntem olduğu söylenebilir. Ancak, bu yaklaşım yaygın 
olarak kullanılması ile diğer projelerle karşılaştırma imkanı bulabilmektedir. Ülkemizde RAPMASSCOTE çalışmaları yapılmaya başlamış olmasına rağmen bu konu hakkında yayımlanmış bir literatür bulunmamaktadır. RAP-MASSCOTE yaklaşımı, ülkemizde sulama projelerinin izleme ve değerlendirilmesinde oldukça kullanışlı ve yeterli bir yöntem olduğu söylenebilir.

Sonuçta, Kartalkaya Sol Sahil sulama şebekesi birçok performans göstergesinde yüksek performans göstermiştir. Bu göstergeleri çiftçilerin görüşleri desteklemektedir. Araştırma alanında bazı değişikliklerle performansın arttırılması mümkündür. Sekonder kanalların yıpranan, kırılan bölgelerinden veya yabancı otların artmasından kaynaklanan sızıntıların önlenmesi gerekmektedir. Su dağıtım teknisyenlerine daha adil su dağıtımı yapmaları için pratik kullanabilen debi ölçer kullanmaları teşvik edilmelidir. Sulama alanında çiftçilere suyun verimli kullanılması için modern sulama tekniklerine yönelmeleri sağlanmalıdır. Böylece, sulama şebekesinde sulanan alanın artması sağlanmış olacaktır. Böylelikle tarımsal üretim değeri artacak, ülke ekonomisine katkıda bulunulacaktır. Dünyada azalan tatlı su kaynaklarının büyük çoğunluğu tarımda kullanan ülkelerden biri olarak, Türkiye'de suyu etkili ve verimli kullanmak için sulama şebekelerinin izleme ve değerlendirme çalışmaları yapılmaktadır. $\mathrm{Bu}$ çalışmalar, ancak RAPMASSCOTE gibi doğru yöntem ve yaklaşımlarla başarıya ulaşabilir.

\section{TEŞEKKÜR}

$\mathrm{Bu}$ çalışma 2016/3-32 yüksek lisans proje numarası ile BAP tarafından desteklenmiştir. Ayrıca bu çalışmaya katkılarından dolayı Kartalkaya Sol Sahil Sulama Birliği ve çalışanlarına teşekkür ederiz.

\section{KAYNAKLAR}

Abdullah, M. Y., Soom, M. A. M., Abdullah, S. 2007. A Case Study for Tanjung Karang Rice Irrigation Scheme Malaysia. Aplication of MASSCOTE Aproach on Modernization of Irrigation System. http://www.rid.go.th/thaicid/_6_activity/TechnicalSession/SubTheme1/1.06-M_Yazid_A-M_Amin_MSS_Abdullah.pdf Son erișim: 13.07.2016

Beyribey, M. 1997. Devlet Sulama Şebekelerinde Sistem Performansının Değerlendirilmesi. A.Ü. Ziraat Fakültesi Yayın No: 1480, Bilimsel Araştırmalar ve İncelemeler. 813. Ankara

Borgia, C., García-Bolaños, M., Li, T., Gómez-Macpherson, H., Comas, J., Connor, D., Mateos, L. 2013. Benchmarking for Performance Assessment of Small and Large Irrigation Schemes Along the Senegal Valley in Mauritania.Agricultural Water Management, 121, 19-26.

Burt, C. M., Styles, S. W. 1998. Modern Water Control and Management Practices in Irrigation: Impact on Performance. Report No. R 98-001.
Burt, C. 2001. Rapid Appraisal Process (RAP) and Benchmarking: Explanation and Tools. Water Control. http://www.watercontrol.org/tools/rap-eng-2002 Son erişim tarihi: 18 Ağustos 2014.

Clemmens, A. J., Molden, D. J. 2007. Water Uses and Productivity of Irrigation Systems. Irrigation Science, 25(3), 247-261.

Çakmak, B. 2002. Ceylanpınar İkicırcıp Sulama Birliği'nde Sulama Sistem Performansının Değerlendirilmesi. Harran Üniversitesi Ziraat Fakültesi Dergisi, Cilt:7, Sayı:1-2, s.1-9, Şanliurfa.

Değirmenci, H. 2001. Devredilen sulama sebekelerinin karşılaştırma göstergeleri ile değerlendirilmesi. Uludağ Üniversitesi Ziraat Fakültesi Dergisi,15, 31-41.

Değirmenci, H. 2004. Kahramanmaraş Bölgesinde Bazı Sulama Şebekelerinin Karşılaştırma Göstergeleri ile Değerlendirilmesi. KSÜ Fen ve Mühendislik Dergisi, 7(1), 104-110.

Değirmenci, H. 1997. Sulama Yönteminde İzleme ve Değerlendirmenin Etkinliği Üzerine Bir Araştırma. Uludağ Üniversitesi Fen Bilimleri Enstitüsü Tarımsal Yapılar ve Sulama Anabilim Dalı Doktora Tezi, 2s, Bursa.

DSİ. 2015a. DSİ 2015 Yılı Faaliyet Raporu. Devlet Su İșleri Genel Müdürlüğ̈. http://www.dsi.gov.tr/docs/stratejikplan/dsi-2015-faaliyet-raporu.pdf?sfvrsn=2\#page $=71 \quad$ Son erişim: 07.08.2016

DSİ. 2015b. Mahsul Sayım Sonuçları, İzleme ve Değerlendirme Raporu, Faaliyet Raporu, Planlı Su Dağıtım Raporları. DSİ 20. Bölge Müdürlüğü İşletme ve Bakım Şubesi. Kahramanmaraș.

FAO, 2009. Masscote Aplications in Upper Krishna ProjectKJBNL. Modernization Strategy for Irrigation Management. Food and Agriculture Organization of the United Nations. Rome, 2009.

ITRC. 2016. Rapid Appraisal Process (RAP) and Benchmarking BLANK.xls (EXCEL Document). Rapid Aprasial Process. Irrigation Training and Research Center http://www.itrc.org/reports/rap041803.htm Son erişim 21.07.2016

Konukcu, M., Sener, A. Y. F. 2007. Evaluation of Hayrabolu irrigation scheme in Turkey using comparetive performance indicators. JOTAF/Tekirdağ Ziraat Fakültesi Dergisi, 4(1), 43-54.

Miran, B., 2003. Temel İstatistik. Ege Üniversitesi Basımevi, ISBN975-9308800 Bornova İzmir. s. 324.

Molden, D. J., Sakthivadivel, R., Christopher, J. Perry, C. J. de Fraiture, C. 1998. Indicators for Comparing Performance of Irrigated Agricultural Systems. Research Report 20, IWMI Publications, Colombo, Sri Lanka.

Murray-Rust, D. H., Svendsen, M. 2001. Performance of Locally Managed Irrigation in Turkey: Gediz Case Study. Irrigation and Drainage Systems, 15(4), 373-388.

Nalbantoğlu, G. 2006. Akıncı Sulama Birliğinde Sulama Performansının Karşılaştırmalı Değerlendirilmesi. Ankara Üniversitesi Fen Bilimleri Enstitüsü Tarımsal Yapılar ve Sulama Ana Bilim Dalı Yüksek Lisans Tezi, 42s, Ankara.

Nalbantoğlu, G., Çakmak, B. 2007. Akıncı Sulama Birliğinde Sulama Performansının Karşılaştırmalı Değerlendirilmesi Ankara Üniversitesi Ziraat Fakültesi Tarım Bilimleri Dergisi 13: 213-223

Renault, D., Facon, T., Wahaj, R. 2007. Modernizing Irrigation Management - the MASSCOTE Approach. FAO Irrigation and Dranage Paper 63, 238.

Sönmezyıldız, E., Çakmak, B. 2013. Eskişehir Beyazaltın Köyü Arazi Toplulaştırma Alanında Sulama Performansının Değerlendirilmesi. Akdeniz Üniversitesi Ziraat Fakültesi Dergisi, 26(1), 33-40.

Tanrıverdi, Ç.,Degirmenci, H. ve Sesveren, S. 2011. Assessment of Irrigation Schemes in Turkey Based on Management Types. African Journal Of Biotechnology Vol. 10(11) 1997-2004. 